\title{
Adrenal disease: a clinical update and overview of imaging. A review
}

\author{
Filip Ctvrtlika , Pavel Koranda ${ }^{b}$, Tomas Tichyc
}

\begin{abstract}
Aim. The aim of this article is to provide an overview of the most frequent clinically significant adrenal diseases and to describe the latest trends in their diagnostics, particularly by means of imaging techniques.

Methods. The authors reviewed standard textbooks and subsequently conducted a search using the PubMed (Public/ Publisher MEDLINE) electronic database by the year 2013 with the following search terms: adrenal masses, adrenal adenoma, phaeochromocytoma, adrenocortical carcinoma, metastases, incidentalomas, hypercortisolism, hyperaldosteronism.

Results. If adrenal disease is clinically suspected, hormone tests are performed to detect adrenal hyperfunction and imaging studies are used to assess the nature of adrenal lesion. The most frequent syndromes include hypercortisolism, primary hyperaldosteronism, and phaeochromocytoma. The clinically most significant pathologies of the adrenal glands are adenomas and adrenal hyperplasia, adrenocortical carcinomas, phaeochromocytomas, and metastases. Given the availability and improved quality of imaging techniques, adrenal incidentalomas are detected increasingly often. In these cases, it is necessary to rule out hormonal activity and malignancy. Incidentalomas can be associated with clinical syndromes of adrenal hormone overproduction. In most cases, they are clinically silent. In some cases, the definitive diagnosis can be determined as early as during the initial examination with an imaging technique (most frequently, a CT scan). If the finding is inconsistent, other imaging techniques can be used: CT contrast washout analysis, $\mathrm{MRI}, \mathrm{SPECT}$ or PET/CT.
\end{abstract}

Conclusion. In the case of adrenal gland disorders, correct interpretation of the results of laboratory tests and imaging studies is essential for further management of these patients.

Key words: adrenal masses, adrenal adenoma, phaeochromocytoma, adrenocortical carcinoma, metastases, incidentalomas, computed tomography, PET/CT

Received: September 23, 2013; Accepted: February 13, 2014; Available online: February 20, 2014 http://dx.doi.org/10.5507/bp.2014.010

${ }^{a}$ Department of Radiology, University Hospital Olomouc and Faculty of Medicine and Dentistry, Palacky University Olomouc, Czech Republic ${ }^{b}$ Department of Nuclear Medicine, University Hospital Olomouc and Faculty of Medicine and Dentistry, Palacky University Olomouc 'Department of Clinical and Molecular Pathology, University Hospital Olomouc and Faculty of Medicine and Dentistry, Palacky University Olomouc

Corresponding author: Filip Ctvrtlik, e-mail: Filip.Ctvrtlik@fnol.cz

\section{INTRODUCTION}

The management of adrenal diseases has recently undergone major development as a result of rapid advances in laboratory and, in particular, imaging techniques. The available therapeutic options are also improving. If adrenal disease is suspected clinically, the diagnostic algorithm initially involves hormone tests to detect adrenal hyperfunction. These are then followed by imaging studies addressing the morphological presentation of adrenal pathology, including evaluation of adjacent structures (Fig. 1).

Given the ever improving availability of imaging techniques, the issue of adrenal incidentalomas is increasingly relevant. In contrast to cases presenting with clinical symptoms, the incidental finding on imaging studies is the first detection of pathology, only then followed by a hormone test and a thorough clinical examination focused on the adrenal glands. Incidentalomas can be associated with some of the most common clinical syndromes of adrenal hormone overproduction (hypercortisolism, hyperaldosteronism, or phaeochromocytoma); however, the majority of them are clinically silent.

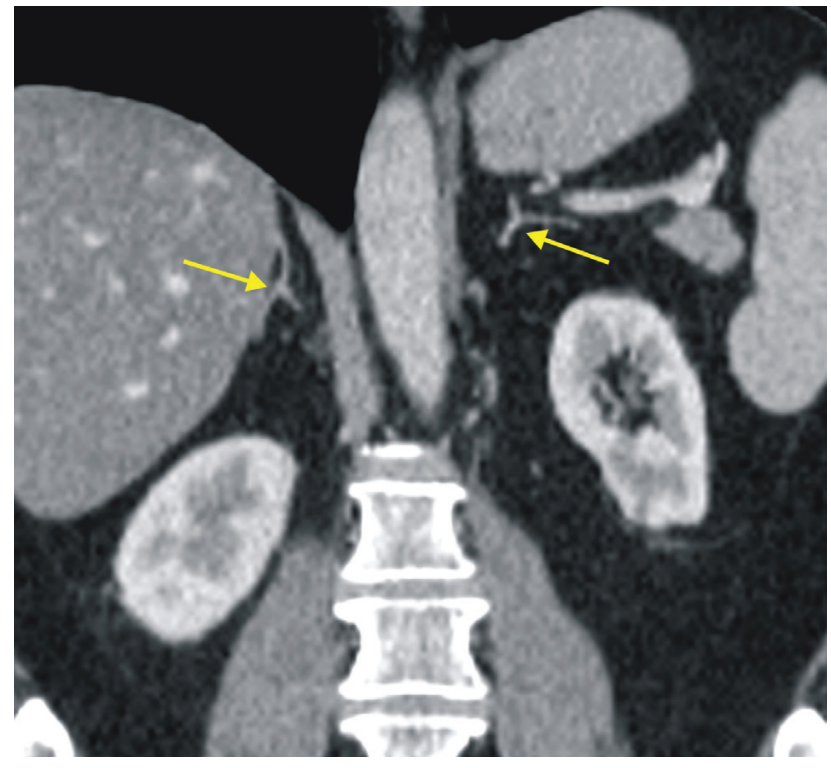

Fig. 1. Normal appearance of the adrenal glands. Normal CT appearance of the adrenal glands in the coronal plane (yellow arrow). 
The most frequent pathologies of the adrenal glands are adenomas and adrenal hyperplasia, most often detected incidentally. Other pathological findings of the adrenal glands include carcinomas, phaeochromocytomas, and metastases. It is essential to distinguish adrenal adenomas from these entities since they usually require a different therapeutic approach.

The aim of this article is to provide an overview of the most frequent clinically significant adrenal diseases and to describe the role of imaging techniques in diagnosing these conditions.

\section{ADENOMA}

Adenoma is the most frequent adrenal tumour; it is of a benign nature. In the majority of cases, it is found incidentally on imaging and exhibits no hormonal activity. When hormonally active, it may produce cortisol or aldosterone. Adenomas can be accompanied by the following clinical syndromes: hypercortisolism and hyperaldosteronism.

\section{Hypercortisolism (Cushing's syndrome)}

Cortisol overproduction due to a primary tumour of the adrenal cortex results in the peripheral type of Cushing's syndrome. It is mostly caused by adrenal adenoma, less often by carcinoma ${ }^{1}$. Other types of Cushing's syndrome include the central type (overproduction of ACTH in the pituitary gland) and ectopic ACTH secretion (in some malignant tumours, e.g. small-cell lung carcinoma).

Clinical presentation is nonspecific. Central-type obesity, moon face, and hirsutism can be seen. Purple striae are characteristic. Impaired gonadal function, arterial hypertension, and osteoporosis also occur.

Laboratory screening for Cushing's syndrome utilizes tests for increased 24-h urinary excretion of cortisol and the absence of the normal circadian rhythm of plasma cortisol on the cortisol curve. Dexamethasone suppression tests and adrenocorticotropic hormone (ACTH) tests are also performed. These tests are used not just to confirm the diagnosis of Cushing's syndrome, they also help classify it by its type.

\section{Hyperaldosteronism}

Primary hyperaldosteronism is a condition caused by oversecretion of aldosterone in the adrenal cortex. It is among the most frequent causes of secondary hypertension. It is generally estimated to be present in $5-10 \%$ of patients with arterial hypertension, with some sources reporting as much as $14.4 \%$ of patients ${ }^{2}$. In specialized centres in selected groups of patients with moderate and severe hypertension, the proportion of patients with primary hyperaldosteronism is higher: $5-20 \%$; according to some authors even as much as $37 \%$ (ref., ${ }^{3,4}$ ).

In primary hyperaldosteronism, aldosterone oversecretion is independent of the renin-angiotensin system. Conversely, increased aldosterone secretion in secondary hyperaldosteronism is a result of increased renin produc- tion (such as in diuretic treatment, renal artery stenosis, congestive heart disease, liver cirrhosis, and others). In primary hyperaldosteronism, the following two forms are predominant: one caused by aldosterone-producing adenomas of the adrenal cortex (Conn's syndrome) and another called bilateral adrenal hyperplasia. The distinction between these two most common causes of primary hyperaldosteronism is absolutely essential for correct therapeutic approach. Adrenal adenoma is indicated for surgical treatment, i.e. adrenalectomy. In contrast, bilateral hyperplasia is treated medically. Laboratory distinction between the two types of primary hyperaldosteronism is not possible and, unfortunately, even the results of imaging studies (adrenal CT or MRI) are often equivocal ${ }^{5,6}$. The gold standard for distinguishing these two types of primary hyperaldosteronism is adrenal vein catheterization with sequential blood sampling to determine aldosterone and cortisol levels. This determines whether hormone overproduction is unilateral or bilateral.

The clinical presentation of primary hyperaldosteronism is nonspecific. Symptoms caused by hypokalaemia may occur: fatigue, paraesthesia, and cardiac rhythm disorders. Moderate to severe arterial hypertension is almost invariably present. Laboratory findings typically include hypokalaemia, elevated potassium excretion, and metabolic alkalosis.

Laboratory tests to measure plasma renin and aldosterone levels are essential. The ratio of plasma aldosterone concentration to plasma renin activity is the most sensitive screening test. Dynamic suppression tests assessing inhibition of aldosterone secretion may also used to confirm the diagnosis.

However, the individual types of primary hyperaldosteronism cannot be distinguished based solely on laboratory methods. Each patient with primary hyperaldosteronism should undergo imaging studies (CT or MRI) in order to rule out adrenocortical carcinoma. However, the finding of imaging studies can still be misleading ${ }^{5,6}$. As a result, most authors tend to recommend that adrenal vein catheterization be performed prior to contemplated adrenalectomy in all patients with primary hyperaldosteronism regardless of the results of imaging studies ${ }^{4,6-10}$.

\section{Finding on imaging studies}

An adenoma is typically of a smaller size. It is usually detected on imaging studies completely incidentally. It is mostly of a homogeneous structure (Fig. 2 a,b).

In general, adenomas can be divided into two groups: lipid-rich adenomas and lipid-poor adenomas. This fact determines the appearance of adenomas on CT and MRI scans $^{11}$

The former group accounts for more than $70 \%$ of adenomas. Owing to a high intracytoplasmic lipid content, it presents with a density lower than 10 Hounsfield units (HU) on an unenhanced CT scan. Unfortunatelly, approximately $30 \%$ of adenomas contain too little lipids and consequently have a higher density on unenhanced CT scans ${ }^{11,12}$.

Adenomas with high content of intracellular lipids can also be detected using chemical shift MRI. Chemical shift 

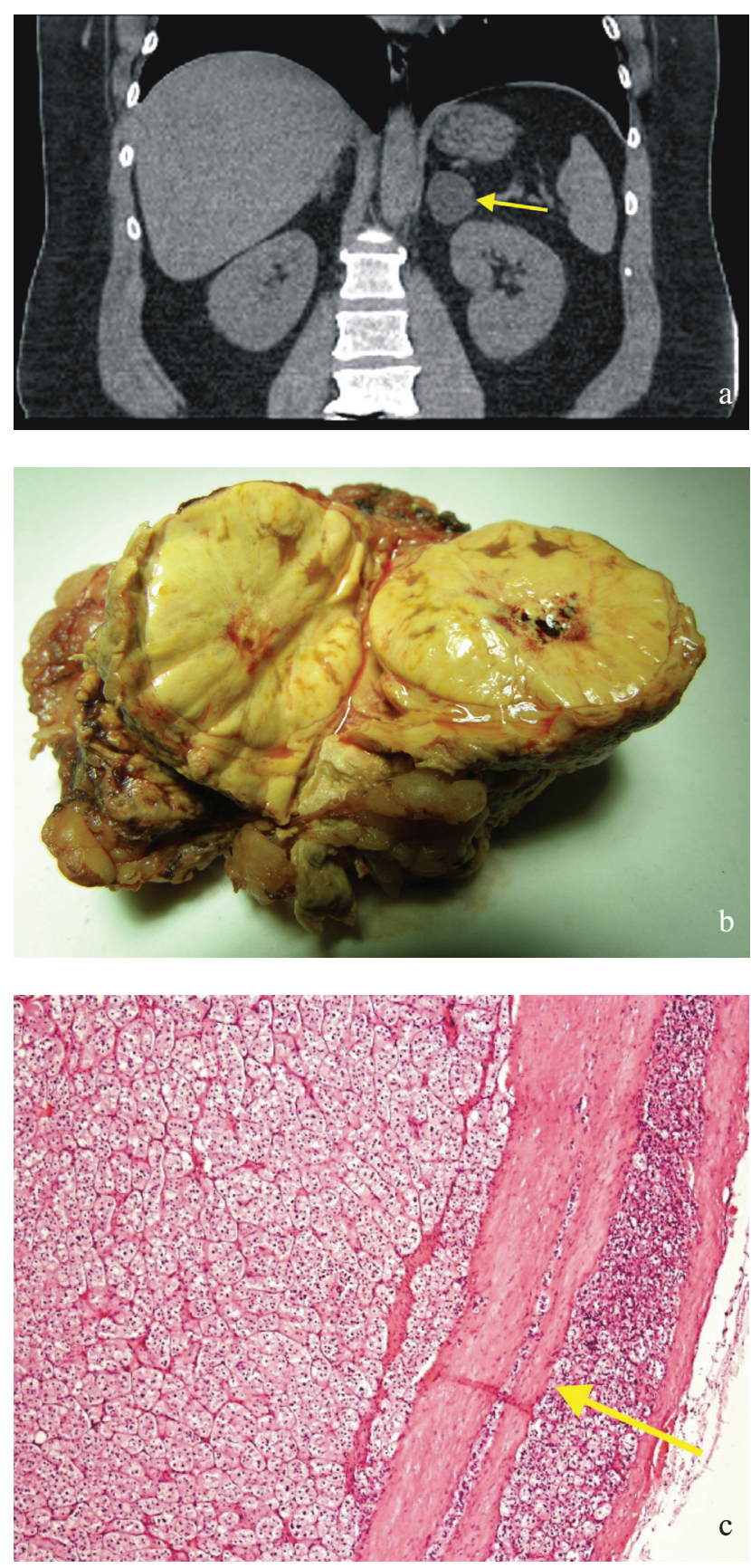

Fig. 2. Adenoma. 2a. CT appearance of left adrenal adenoma in the coronal plane (yellow arrow). 2b. Photograph of a dissected specimen of adrenal adenoma. 2c. Microphotograph of adrenal adenoma. Bright spongiocyte-like cells surrounded by a tough fibrous sheath (yellow arrow). (HE staining, 40x).

works is based on the fact that intensity of signal from water and protons of lipids is additive in in-phase images and subtracts in opposed-phase images. Therefore adrenal adenomas show loss of signal in opposed-phase images compared to in-phase images.

The search for small adrenal tumours in imaging studies (particularly in primary hyperaldosteronism) may present some pitfalls. If the tumors are smaller than the width of the adrenal glands and do not expand extra-adrenally, they may not be apparent at all. Conversely, a false-positive finding may occur, particularly on the right, when the origin of the right suprarenal vein is mistaken for a tumor. According to Matsuura, the origin of the right suprarenal vein is most frequently apparent ventrolaterally ${ }^{13}$, and this is where it can be mistaken for a small adenoma expanding from the adrenal contour (authors' own observation).

On a PET/CT scan, most commonly using ${ }^{18}$ F-fluorodeoxyglucose $\left({ }^{18} \mathrm{~F}\right.$ FDG PET/CT), the vast majority of adenomas do not accumulate the radiopharmaceutical. According to meta-analyses, ${ }^{18} \mathrm{~F}$ FDG PET/CT scanning generally has a high sensitivity (97\%) and specificity (91\%) in distinguishing between a malignant and benign adrenal lesion ${ }^{14}$.

Unilateral or bilateral adrenal hyperplasia may also have a similar appearance to adrenal adenoma(s) on imaging studies. A definitive distinction of adenoma from hyperplasia is not possible by means of imaging techniques (Fig. 3a). The finding may not be unequivocal even on histopathological examination since the hyperplastic nodule can be encapsulated. The evaluation must be comprehensive and includes the presence/absence of a continuous capsule, signs of expansive growth with compression atrophy of the surrounding tissue, and the number of foci, with a solitary nodule being rather indicative of adenoma and multiple ones of hyperplasia. (Fig. 2a, 3b) Clinical decision making is significantly aided by finding of unilateral hormone overproduction.

\section{MYELOLIPOMA}

Myelolipomas are benign adrenal tumours. They consists of two parts: fatty and haematopoietic tissues (Fig. 4b). They are hormonally silent and clinically asymptomatic, with only large myelolipomas manifesting by pain or by retroperitoneal haemorrhage. Myelolipomas grow very slowly. They require no treatment; only larger symptomatic myelolipomas may require surgical removal.

\section{Finding on imaging studies}

Owing to their lipid content, myelolipomas typically have low density on CT scans, lower than $0 \mathrm{HU}$, or often less than $-50 \mathrm{HU}$. Because of the presence of haematopoietic tissue, their density is slightly higher than that of the surrounding retroperitoneal fat. Their MRI appearance corresponds to that on CT scans. Due to its typical appearance, the diagnosis of myelolipoma can be definitive based only on CT or MRI finding (Fig. 4a). It does not accumulate the radiopharmaceutical on ${ }^{18} \mathrm{~F}$ FDG PET/CT.

\section{PHAEOCHROMOCYTOMA}

Phaeochromocytomas are tumours of chromaffin cells of the sympathoadrenal system with sustained or paroxysmal catecholamine hypersecretion causing arterial hypertension. They most commonly arise in the adrenal medulla, but can also occur extra-adrenally (these tumours are referred to as paragangliomas). The majority of phaeochromocytomas are benign. 

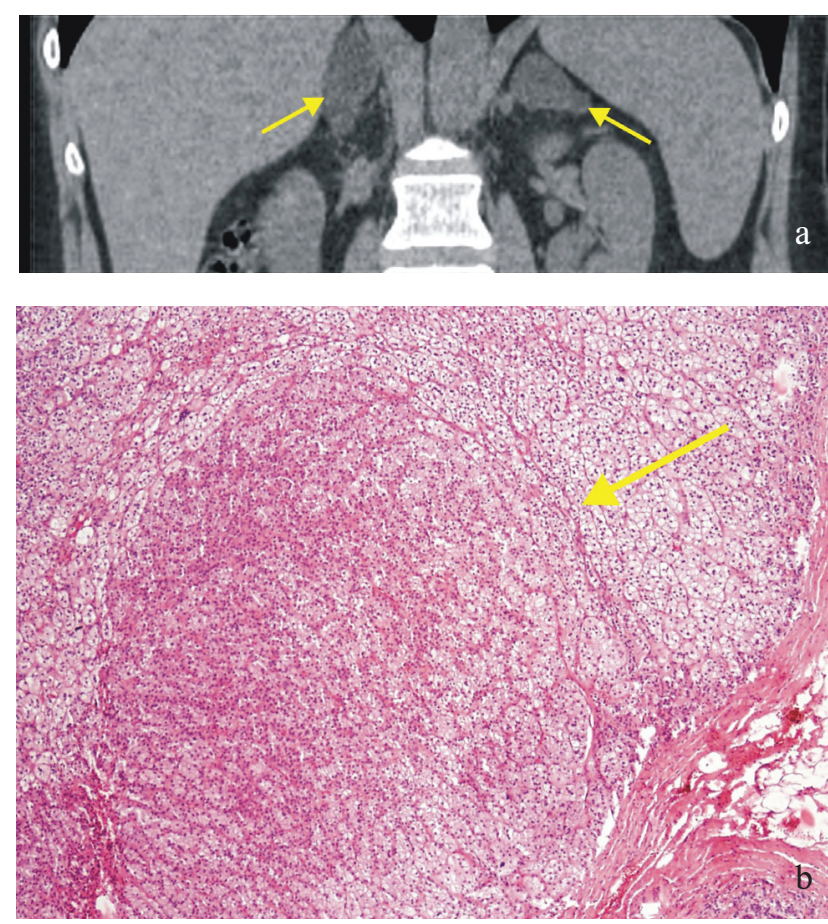

Fig. 3. Adrenal hyperplasia. 3a. CT appearance of bilateral adrenal hyperplasia in the coronal plane (yellow arrow). $3 \mathrm{~b}$. Microphotograph of cortical adrenal hyperplasia. An unencapsulated cortical nodule consisting of a mixture of bright spongiocyte-like cells and cells with eosinophilic cytoplasm (yellow arrow). (HE staining, 40x).
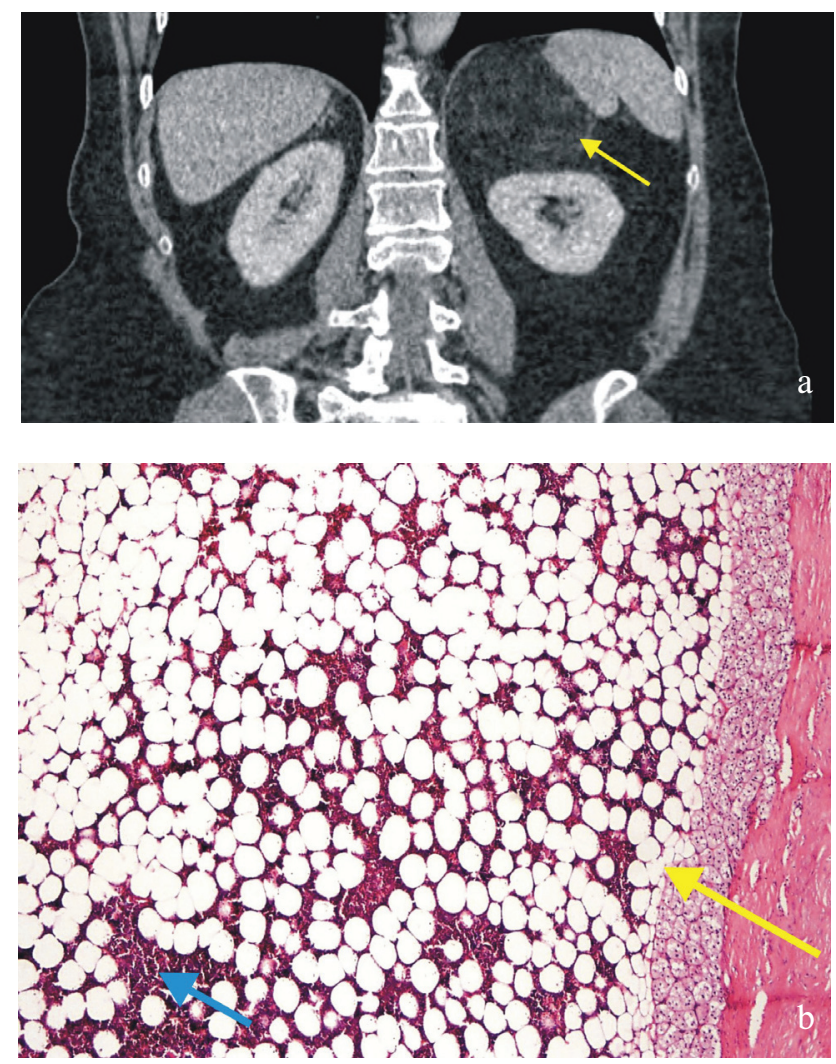

Fig. 4. Myelolipoma. 4a. CT appearance of left adrenal adenoma in the coronal plane (yellow arrow). 4b. Microphotograph of adrenal myelolipoma. The tumour consists of mature adipose tissue (yellow arrow) with a variable admixture of haematopoietic cells (blue arrow). (HE staining, 40x).
The prevalence of phaeochromocytomas is estimated to range from $1: 4,500$ to $1: 1,700$ with an annual incidence of 3-8 cases per 1 million population ${ }^{1}$. Seventy to seventy-five percent of phaeochromocytoma cases arise in the adrenal gland and $25-30 \%$ occur extra-adrenally ${ }^{15}$. Phaeochromocytomas account for $0.05 \%-0.1 \%$ of cases of sustained hypertension ${ }^{16}$. Approximately $30-35 \%$ of phaeochromocytomas and paragangliomas are hereditary ${ }^{1,17,18}$.

These can be a part of hereditary multiple endocrine neoplasia type 2 (MEN 2) syndrome, occur in neurofibromatosis type 1 (NF-1) and type 2 von Hippel-Lindau (VHL 2) syndrome, or be associated with hereditary paragangliomatosis with succinate dehydrogenase (SDH) gene mutations $^{1,19-22}$. In SDHB gene mutations, recurrent, aggressive, and metastatic paragangliomas develop ${ }^{1,23}$.

Distinguishing the biological nature of phaeochromocytoma by means of imaging techniques alone is impossible in most cases. If distant metastases are present, a malignant form can be expected. The distinction between benign and malignant phaeochromocytomas is very difficult even for a histopathologist (Fig. $5 \mathrm{~d}$, e). It is necessary that the evaluation be done by a pathologist experienced in assessment of adrenal tissue. When evaluating the specimen, it is not sufficient to use only the principles of general oncology. Histological evaluation must be comprehensive and include immunohistochemical examination of proliferation activity. Only then the possibility of recurrence or metastases can be addressed with a certain degree of likelihood ${ }^{24}$. However, conclusive histopathological signs of malignant phaeochromocytoma generally remain controversial. Long-term surveillance of patients following surgery for phaeochromocytoma is therefore warranted. Inadequate surveillance is still the most common error in postoperative follow-up care of phaeochromocytoma patients. When no long-term regular check-ups of clinical status, biochemical markers and imaging techniques are carried out, patients with unrecognized malignant phaeochromocytoma may present after several years with already generalized disease.

The clinical signs of phaeochromocytoma tend to be varied. The presentation of a phaeochromocytoma typically includes sustained or paroxysmal hypertension, often resistant to standard treatment. Headaches, sweating, palpitations, chest pain, shortness of breath, cold and wet skin, pallor, tremor, anxiety, nervousness, and dyspeptic complaints can all occur during a paroxysm. In untreated phaeochromocytomas, neuroretinopathy, cardiomyopathy, and stroke may develop. Determination of free plasma normetanephrine and metanephrine is the gold standard in diagnosing catecholamine hypersecretion $^{25,26}$. When available, levels of free methoxytyramine can be used ${ }^{1,27,28}$. If the values of these markers are not convincing, the clonidine test can be used to confirm the diagnosis. This test is also capable of identifying patients with falsely elevated catecholamines ${ }^{29}$. Caffeine, an aminerich diet, and some drugs, particularly tricyclic antidepressants are significant sources of false-positive results of catecholamines and metanephrine $\mathrm{e}^{30}$.

Once the diagnosis of phaeochromocytoma has been established, proper preparation is vital prior to its surgi- 

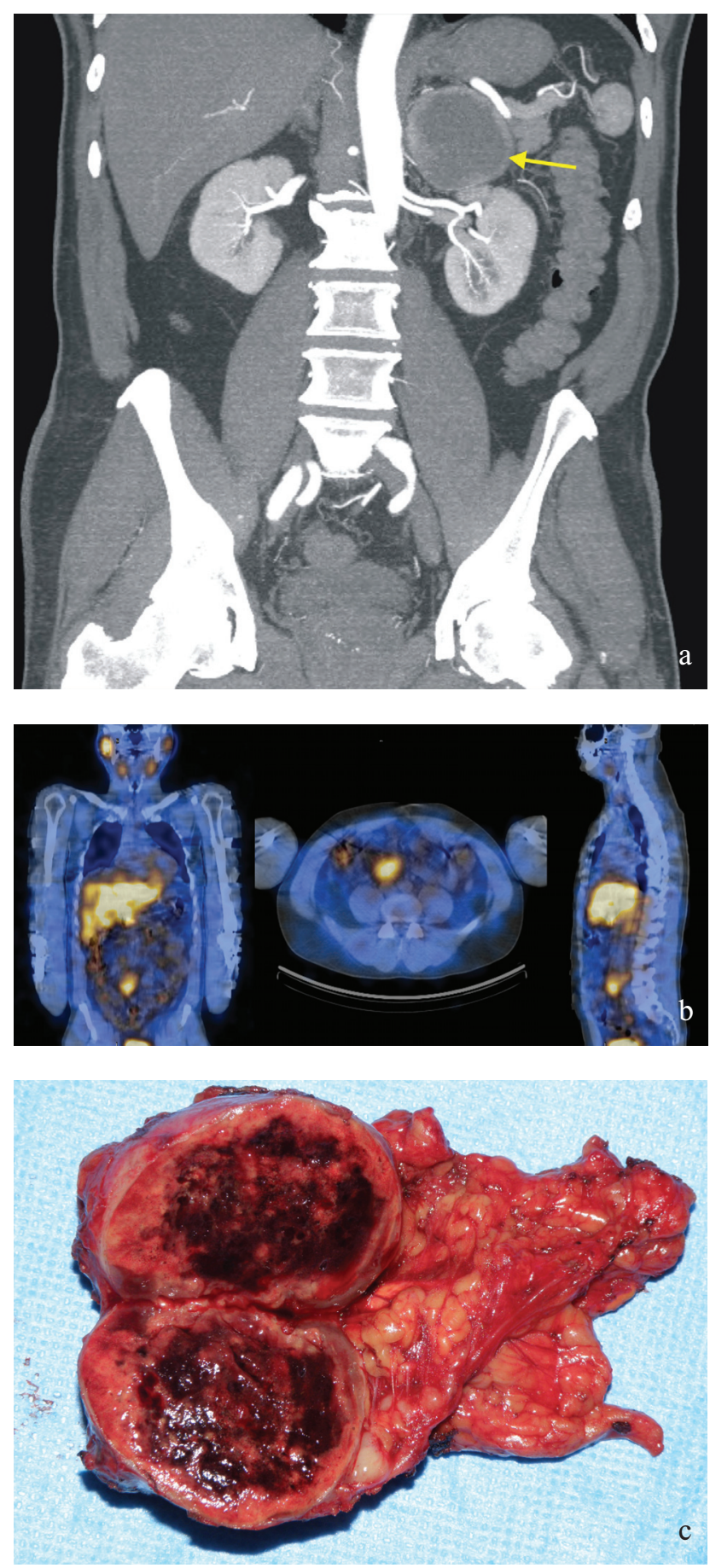

cal removal in order to reduce the risk of perioperative complications. Pharmacotherapeutic preparation of the patient significantly (as much as tenfold) reduces the risk of perioperative mortality ${ }^{31}$. Administration of an alpha blocker to limit vasoconstriction is fundamental. If required, a beta blocker is added prior to surgery to prevent tachycardias. The administration of a beta blocker must not be initiated prior to induction of alpha blockade due to risk of severe hypertension. Given the risk of complications, anaesthesia during surgery for phaeochromocytoma should be administered by an experienced anaesthesiologist.
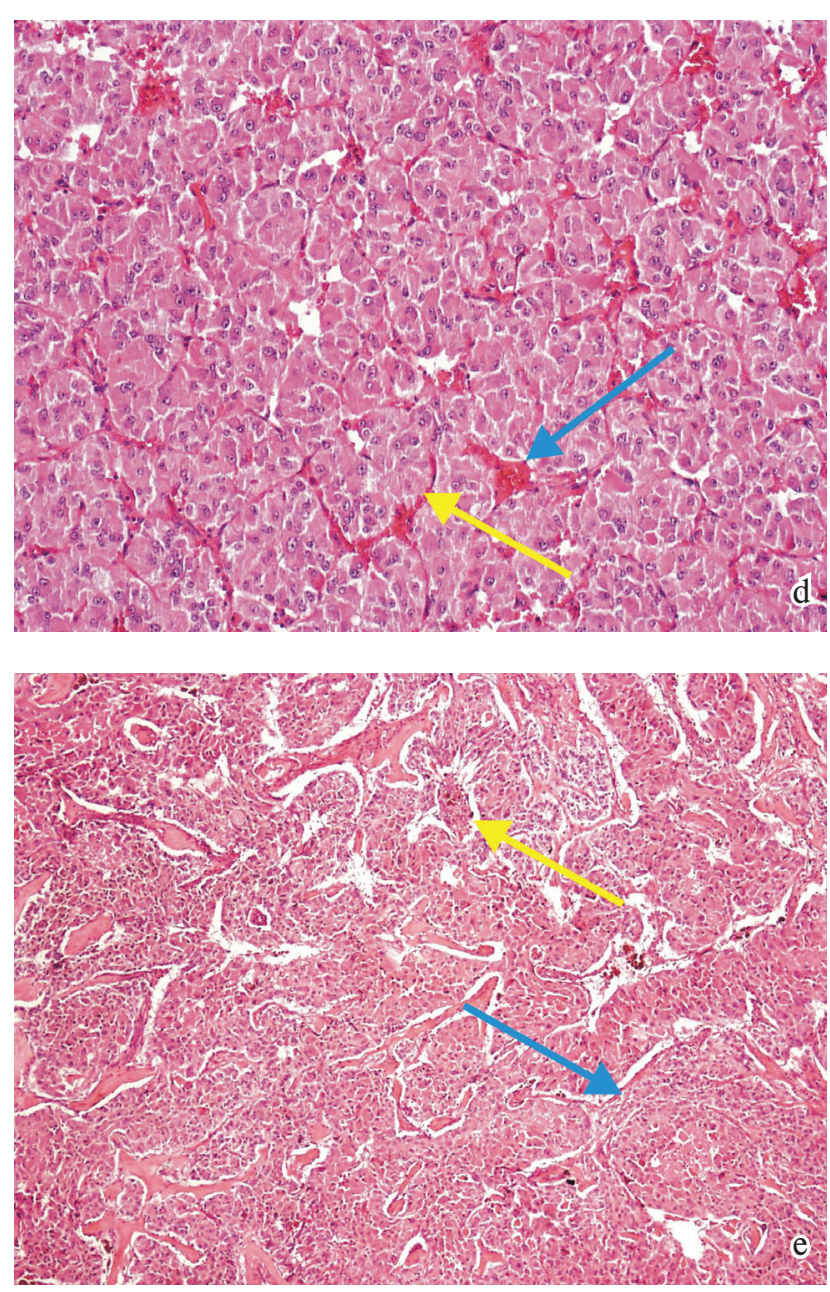

Fig. 5. Phaeochromocytoma. 5a. CT appearance of left adrenal phaeochromocytoma in the coronal plane (yellow arrow). 5b. MIBG/SPECT appearance of extra-adrenal phaeochromocytoma in the coronal, axial, and sagittal planes. 5c. Photograph of a dissected specimen of adrenal phaeochromocytoma. $5 \mathrm{~d}$. Benign phaeochromocytoma. Detail of tumour cells of compact tumour nests (yellow arrow) delimited by a dense sinusoidal capillary network (blue arrow). The cell nuclei are uniform (however, nuclear polymorphism in benign phaeochromocytoma is frequent and is not a marker of malignancy. The evaluation of malignancy is comprehensive). (HE staining, 100x). 5e. Malignant phaeochromocytoma. The tumour is composed of irregular solid nests (blue arrow) of cells with nuclear polymorphism; tumour necroses (yellow arrow) and vascular invasions were present in the central part of the tumour. Ki-67 proliferative activity reached $20 \%$. (HE staining, 40x).

\section{Finding on imaging studies}

Like carcinomas, phaeochromocytomas tend to be larger in size. They are soft-tissue expansions that often contain necrotic parts. Following the administration of a contrast medium, there is often very intensive heterogeneous enhancement on CT or MRI with appearance of necrotic areas (Fig. 5a). An unequivocal distinction from a carcinoma or a metastasis based only on imaging techniques is not possible. Likewise, it is not possible to clearly distinguish benign from malignant variants of phaeochromocytoma. Only in patients in whom distant metastases are detected, a malignant phaeochromocyto- 

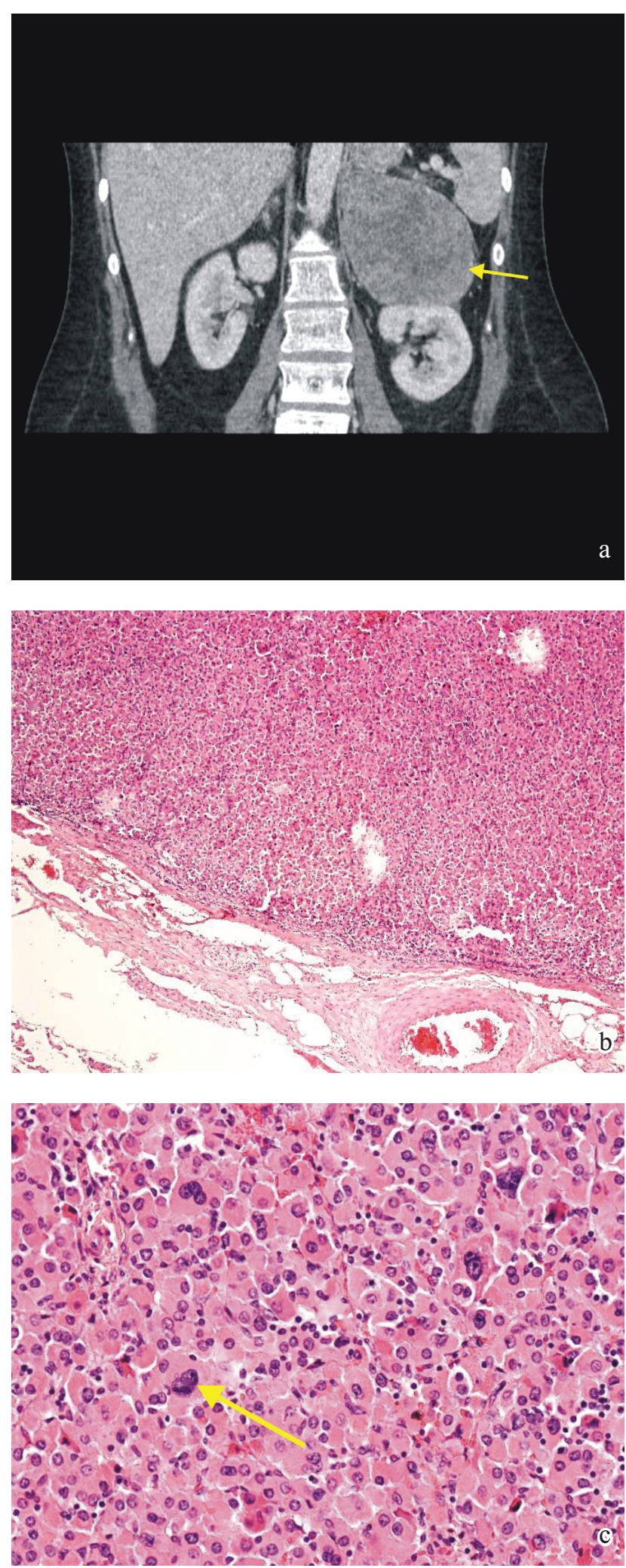

Fig. 6. Adrenal carcinoma. 6a. CT appearance of left adrenal carcinoma in the coronal plane (yellow arrow). 6b. Adrenocortical carcinoma. The tumour is composed of solid trabecular and solid alveolar parts. Nuclear polymorphism may or may not be detected and does not represent a conclusive sign of malignancy. Large necroses as well as capsular and vascular invasions were found to be present in the tumour. Ki-67 proliferative activity reached $30 \%$. (HE staining, 40x). 6c. Adrenocortical carcinoma. Detail of tumour cells with eosinophilic cytoplasm and nuclear polymorphism (yellow arrow). (HE staining, 200x).
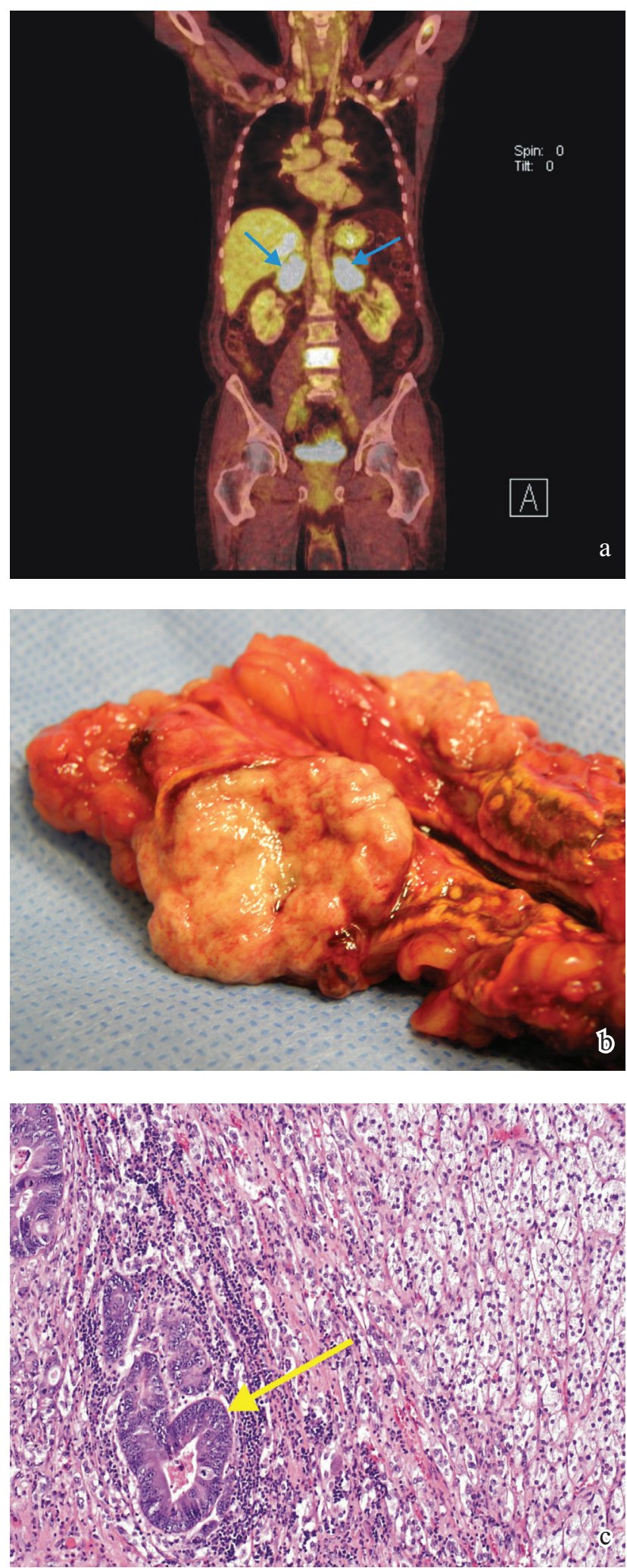

Fig. 7. Adrenal metastasis. 7a. PET/CT appearance of metastases in both adrenal glands in the coronal plane (blue arrow). 7b. Photograph of a dissected specimen of metastasis in the adrenal gland. 7c. Metastasis of adenocarcinoma (yellow arrow). (HE staining, 100x). 
ma can be suspected. The mean five-year survival rate in malignant phaeochromocytoma ranges from $40 \%$ to $60 \%$ (ref. ${ }^{1}$ ). A previously held misconception concerning the possibility of inducing hypertensive crisis following the administration of contrast medium has been refuted ${ }^{32}$. A biopsy, on the other hand, significantly inreases the risk of catecholamine release into circulation. Therefore, a biopsy is contraindicated when phaeochromocytoma is clinically suspected. MRI can also be used to investigate phaeochromocytoma, but previously described classical T2 hyperintense phaeochromocytomas are relatively uncommon. A wide range of appearances of adrenal phaeochromocytomas on T2-weighted MRI has been described ${ }^{33}$. MRI has the advantage of absence of ionizing radiation but the drawback is a larger number of contraindications compared to CT.

The issue of imaging phaeochromocytomas and paragangliomas using methods of nuclear medicine is a rather complex one ${ }^{34}$. In most cases, the tumours accumulates the radiopharmaceutical on ${ }^{18} \mathrm{FDG}$ PET/ CT scans. Scintigraphy with radioactive iodine-labelled metaiodobenzylguanidine ${ }^{123}$ I-MIBG can also be utilized for detection (Fig. 5b) (ref. ${ }^{35,36}$ ). ${ }^{123} \mathrm{I}-\mathrm{MIBG}$ may fail to detect adrenal phaeochromocytoma associated with von Hippel-Lindau syndrome. In these cases, it is possible to use PET with $18 \mathrm{~F}$-fluorodopamine or 18F-fluorodihydroxyphenylalanine with higher sensitivity than scintigraphy with MIBG (ref. ${ }^{37}$ ). Routine use, however, is still hindered by low availability and high costs. Unfortunately, some phaeochromocytomas have lost their membrane noradrenergic transport system and fail to uptake these markers ${ }^{1}$.

\section{ADRENOCORTICAL CARCINOMA}

Adrenocortical carcinoma (ACC) is a less frequent, but clinically very significant adrenal tumour with a high malignancy potential. The incidence of adrenal carcinoma is reported to be 1 to 2 cases per 1 million population ${ }^{38}$; the prevalence is estimated to be $4-12$ cases per 1 million population ${ }^{39}$. It occurs slightly more in women $(1.5: 1)$ (ref. $\left.{ }^{40}\right)$.

In $50-60 \%$ of patients, adrenocortical carcinomas manifest by adrenal hyperfunction ${ }^{38}$. Most commonly, it is Cushing's syndrome which occurrs in $30-45 \%$ of hormonally active ACCs (ref. ${ }^{41}$ ). Unlike benign adrenocortical tumours, carcinomas may produce several groups of steroids $^{42}$. Histopathological diagnosis is not simple and it is advisable that it be done by a pathologist experienced in this field ${ }^{43}$. When evaluating the malignant nature of an adrenocortical tumour, both clinical manifestations and macroscopic as well as microscopic features of the tumour need to be taken into consideration. Histological signs of malignancy include diffuse pattern of growth, vascular and capsular invasion, tumour necroses, increased mitotic activity, cellular polymorphism, and high proliferation activity detected by immunohistochemical analysis. In order to classify the tumour as malignant, the presence of several of the above-mentioned signs is usually required. For example, nuclear polymorphism can be quite minimal and vascular invasion may not be apparent in a given sample (Fig. 6b,c).

Despite complete resection in stage I-III tumours, approximately $40 \%$ of patients develop metastasis within two years ${ }^{44}$.

\section{Finding on imaging studies}

Adrenocortical carcinomas have a significantly larger size in comparison with adenomas (Fig. 5) (ref. ${ }^{45}$ ). They frequently have a strikingly heterogeneous structure on imaging studies. They can invade the surrounding structures and propagate to the adrenal vein, renal vein, or even the inferior vena cava ${ }^{46}$. Substantial progression in size is characteristic. With the use of ${ }^{18} \mathrm{~F}$ FDG PET/CT, increased radiopharmaceutical accumulation is seen in adrenal carcinomas ${ }^{14,47-49}$.

\section{ADRENAL METASTASES}

The adrenal gland is a very well vascularized organ; therefore, it is a frequent site of metastases. On autopsy, metastases into the adrenal glands are found in up to $27 \%$ of patients with malignant epithelial tumours (Fig. 7c) $\left(\right.$ ref. $\left.^{50}\right)$. These most commonly include metastases of bronchogenic carcinoma as well as kidney, breast, stomach, ovarian, and colon cancers (Fig. 7b). In kidney cancer, it can also involve direct invasion of large kidney tumours or those spreading from the upper pole of the kidney. In such cases, it is sometimes difficult to determine whether the case is a kidney tumour invading the adrenal gland or, conversely, an adrenal tumour invading the upper pole of the kidney, which is a less common occurrence (authors' observation). Metastatic involvement of the adrenal glands can be unilateral as well as bilateral. In terms of morphology, metastases exhibit varied appearance and size. They can be just small nodulations, but also large expansions with a strikingly heterogeneous structure.

\section{Finding on imaging studies}

Progression of size is typical for metastases into the adrenal glands. With a larger size, heterogeneous structures are present, which becomes evident particularly following intravenous administration of a contrast medium. Metastases intensively accumulates the radiopharmaceutical on PET/CT scans with ${ }^{18}$ F-fluorodeoxyglucose (Fig. 7a). A significant exception are metastases of malignancies in which the primary tumour does not accumulate this radiopharmaceutical ${ }^{51}$.

\section{GANGLIONEUROMA}

Ganglioneuroma is a benign tumour composed of ganglion cells, occurring predominantly at a younger age. A CT scan typically shows a spherical solid tumour with sharp demarcation. It can contain calcifications ${ }^{52}$. 

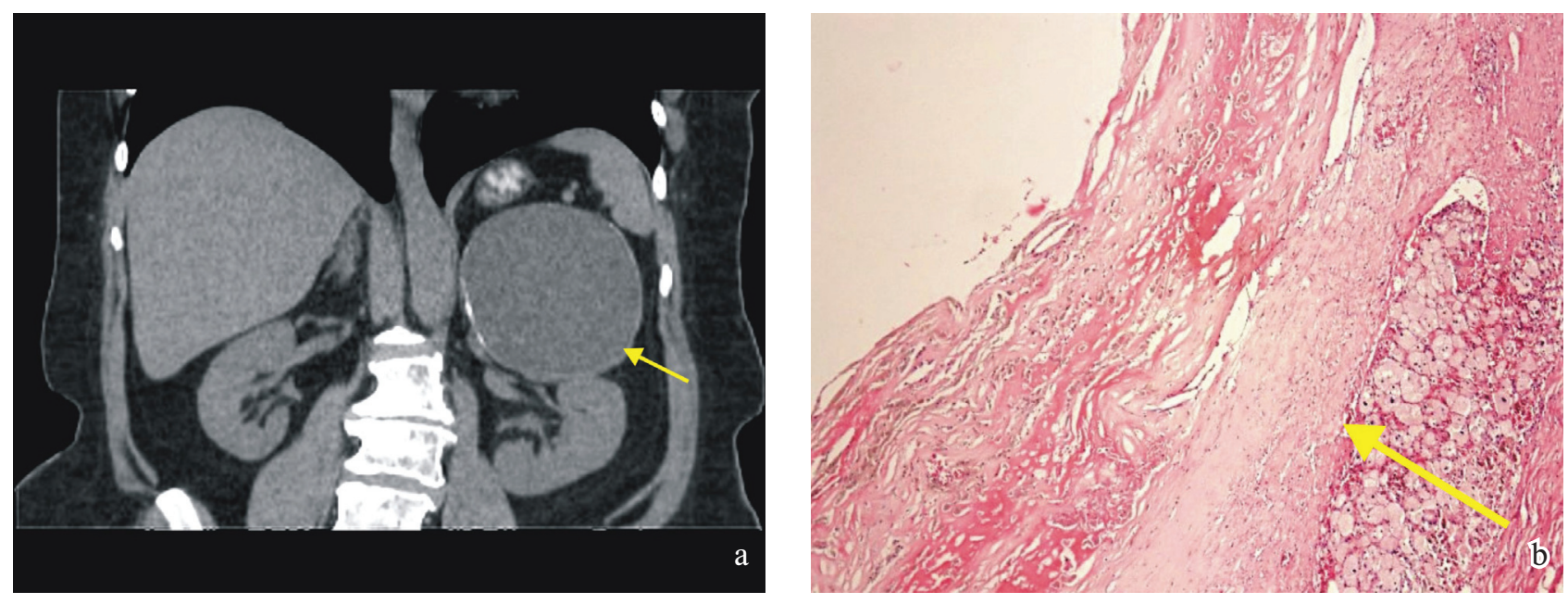

Fig. 8. Adrenal cyst. 8a. CT appearance of left adrenal cyst in the coronal plane (yellow arrow). 8b. Adrenal cyst. Adrenal cysts and pseudocysts can mimic primary and secondary adrenal tumours. The present cyst wall is composed of fibrous tissue (yellow arrow) with calcifications (not shown in the image); the lining is not apparent (thus, in fact, it is a pseudocyst). (HE staining, 40x).

\section{NON-HODGKIN LYMPHOMA (NHL)}

Adrenal lymphoma is one of the less frequent findings. The appearance of adrenal lymphoma on imaging studies is nonspecific. The diagnosis of lymphoma is relevant for the management since the mainstay of treatment is systemic chemotherapy; surgery is not indicated.

\section{CYSTS}

Cysts are a rare finding in adrenal glands. When found, they are often detected incidentally (Fig. 8a). They can be endothelial or, less frequently, epithelial or parasitic. Pseudocysts occurring as a result of bleeding are more frequent (Fig. 8b ) (ref. $\left.{ }^{53}\right)$. If the cyst wall exhibits nodular enhancement on imaging studies, the differential diagnosis must take into consideration a cystic adrenal tumour, in particular phaeochromocytoma and carcinoma ${ }^{53}$.

\section{BLEEDING/HAEMATOMA}

Bleeding into the adrenal glands most commonly occurs in the neonatal period and is rarer in adulthood. It can sometimes be encountered in severe abdominal injury, particularly in polytrauma in which it more frequently occurs on the right side (Fig. 9a) $\left(\right.$ ref. $\left.^{54}\right)$. Furthermore, it can be a complication of adrenal venous sampling ${ }^{55}$. If the involvement is bilateral, it is most commonly associated with coagulation disorders (Fig. 9b) (ref. ${ }^{53}$ ). An incidentally found old adrenal haematoma that can be partially or completely calcified is more typically encountered in adulthood.

\section{TUBERCULOSIS (TB)}

In adults, adrenal involvement occurs as a result of postprimary TB. In the elderly population, adrenal calcifications due to a previous disease may be encountered that can be apparent on a plain radiograph.

\section{NEUROBLASTOMA}

Neuroblastoma is a malignant invasive tumor from the adrenal medulla. It occurs typically in early childhood. Diagnosis is usually done by ultrasound. CT shows large mass exceeding midline. A heterogeneous structure is predominant, with calcifications, necroses and bleeding. The growth of this tumor can occlude large vessels of the retroperitoneum and dislocate surrounding structures. It can spread to the spinal canal or to the inferior vena cava.

\section{ADRENAL INCIDENTALOMAS}

With the ever-increasing availability of imaging techniques, incidental detection of expansions in the adrenal glands becomes increasingly frequent ${ }^{56}$.Adrenal incidentalomas are masses in the adrenal gland incidentally detected by imaging techniques in patients in whom no pathological finding in the adrenal gland was clinically suspected. Incidentalomas are found on abdominal CT scans in approximately $5-10 \%$ of patients (Fig. 10) (ref. ${ }^{57}$ ).

If an adrenal incidentaloma is found, it is important to rule out malignancy and secretory activity. Even at the time of initial detection using an imaging technique (most frequently, a CT scan) the finding should be evaluated by a radiologist regarding its nature. The classic division of incidentalomas into benign and malignant based only on their size (smaller ones - more likely to be benign, larger ones - more likely to be malignant) $\left(\right.$ ref. $\left.^{58}\right)$ is merely 

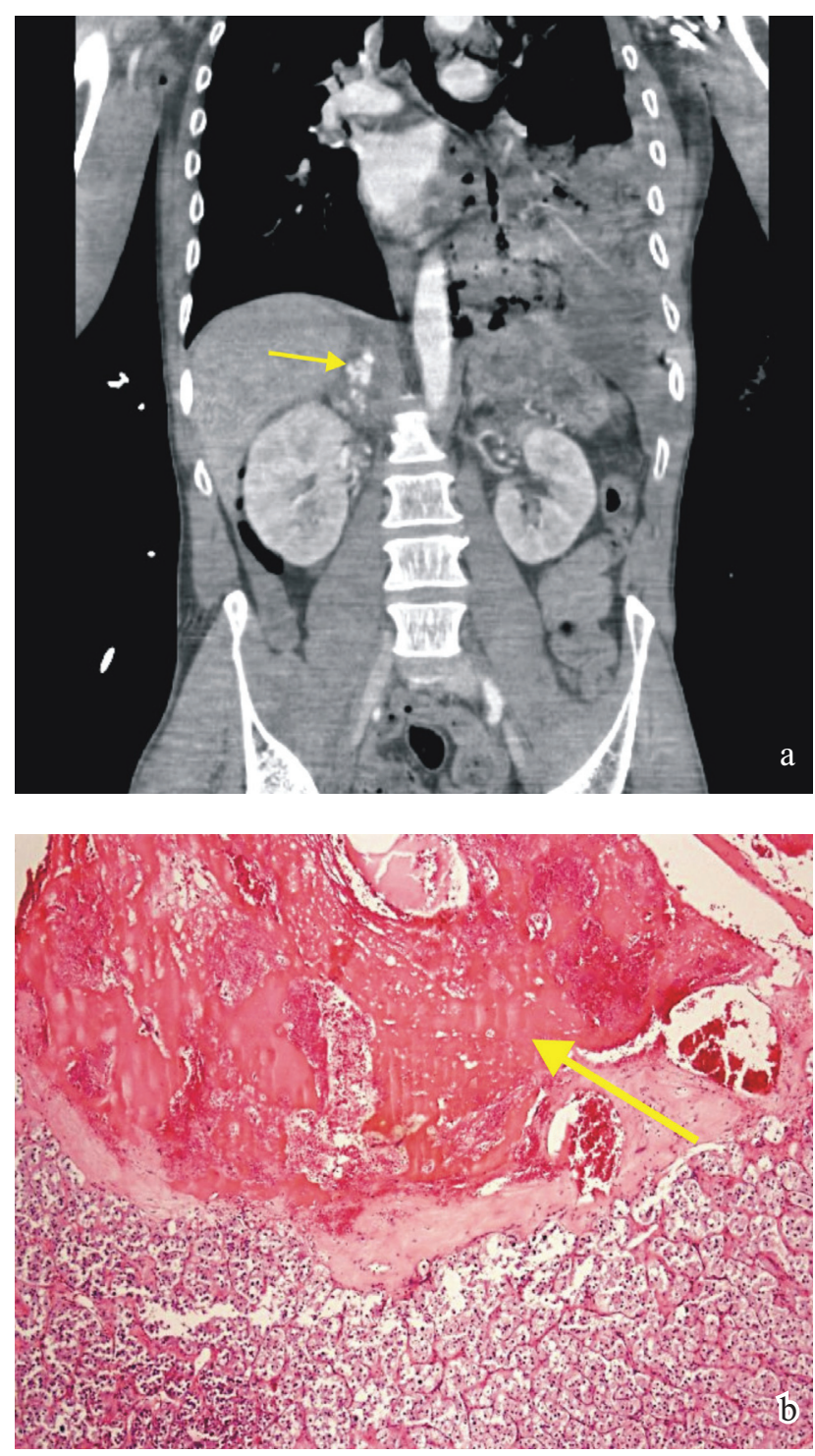

Fig. 9. Adrenal haemorrhage. 9a. CT appearance of active haemorrhage into the right adrenal gland in the coronal plane (yellow arrow). 9b. Adrenal haemorrhage (yellow arrow). A less common condition affecting both children and adults, usually associated with systemic infection and/or hypertension, hypothermia, various shock states, increased bleeding, and trauma. Haemorrhage can also occur in primary and secondary tumours. (HE staining, 40x).

of an indicative value. The primary reason is an overlap in the size of the individual groups ${ }^{59}$. Another reason is related to the increasing general availability of imaging techniques. Given the high examination rates with imaging techniques in the population, incidentalomas tend to be detected much earlier, in comparison with the two previous decades, and thus tend to be of a smaller size. Accordingly, malignant lesions and phaeochromocytomas can also be of a smaller size due to their earlier detection. According to some authors, an adenoma is of a stationary size on imaging studies ${ }^{60}$. However, if observed on CT for several years, many adenomas exhibit clear, even though minimal progression in size.

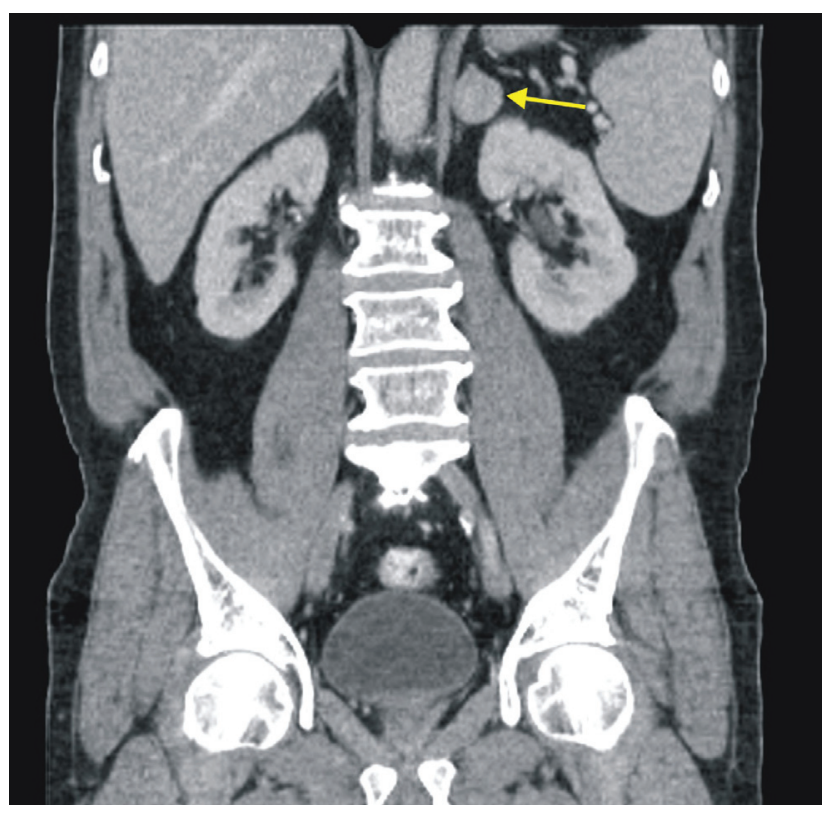

Fig. 10. Left adrenal incidentaloma. CT appearance of left adrenal incidentaloma in the coronal plane (yellow arrow). Hormonal activity confirmed subsequently; phaeochromocytoma identified histologically.

The value of unenhanced density is absolutely crucial in distinguishing adenomas from other adrenal diseases. A low unenhanced density occurring in $70 \%$ of adenomas is caused by a higher cytoplasmic lipid content. It rarely occurs in metastases, adrenocortical carcinomas, and phaeochromocytomas ${ }^{11}$. Based on the value of unenhanced density, incidentalomas can be divided into two groups: adenomas and non-adenomas. The unenhanced density value of $10 \mathrm{HU}$ is, by most authors, considered essential for distinguishing between adenomas and nonadenomas $^{61-64}$.

However, approximately $30 \%$ of adenomas contain small amounts of lipids and thus have a density higher than $10 \mathrm{HU}$ on unenhanced scans. This fact poses a serious differential diagnostic challenge with respect to distinguishing other clinically significant pathological findings with a higher unenhanced density. Thus, an unenhanced CT scan alone cannot be used to distinguish adenoma with a low lipid content from carcinoma, phaeochromocytoma, metastasis, and/or other less frequent adrenal findings (old haematoma, ganglioneuroma, lymphoma, etc.). Since all these pathological findings may have a similar presentation following intravenous administration of a contrast medium, an enhanced scan alone is of no major use in distinguishing these groups. It is useful only if delayed scans with washout characteristics are performed. Adenomas show a rapid washout of contrast medium in comparison with primary carcinomas, metastases, and phaeochromocytomas in which washout of contrast medium is slower ${ }^{65-68}$. An absolute washout of more than $60 \%$ and a relative washout of more than $40 \%$ is indicative of adenoma; conversely, values of absolute washout below $60 \%$ and those of relative washout below $40 \%$ correspond 
to non-adenomas (carcinoma, metastases, phaeochromocytoma) (ref. ${ }^{69-71}$ ). The sensitivity, specificity, and accuracy of washout characteristics in distinguishing adenoma from malignancy are $89-98 \%, 92-95 \%$, and $91-96 \%$, respectively ${ }^{40,68,72-77}$. Calculation of absolute or relative reduction in density can thus be used to distinguish adenomas from non-adenomas. By contrast, delayed scans failed to show differences among these three groups of non-adenomas ${ }^{67}$. Delayed scans are very useful in approximately $30 \%$ of adenomas that do not contain larger amounts of lipids and remain difficult to distinguish by means of unenhanced CT or chemical shift MR imaging ${ }^{67,71}$.

In terms of hormonal activity, adrenal incidentalomas can be divided into two main groups: tumours with no hormonal activity and endocrine-active tumours. The majority are found to be nonfunctional lesions (up to $85 \%$ ) ( ref. $^{78}$ ). Lesions with hormonal activity most typically present by subclinical Cushing's syndrome ${ }^{79}$. Histopathologically, the most commonly detected adrenal incidentalomas are adenomas; other pathological findings (myelolipomas, phaeochromocytomas, carcinomas, metastases, and other rare causes) are less frequent, with the percentages being different in different authors ${ }^{59,80-83}$.

Based on imaging techniques and hormone tests, either surgical management or surveillance of the patient are indicated. Biopsy of the adrenal expansion is associated with general risks and may be of no benefit. Therefore, in the vast majority of cases, further management is determined only based on the morphological presentation on imaging studies and biochemical analysis of secretory activity. Differential diagnosis and correct interpretation of the incidentaloma finding are therefore essential, and the decision-making process particularly important when the patient has already been diagnosed with an extra-adrenal malignancy (e.g., lung carcinoma). In these cases, the distinction of the nature of the lesion is absolutely crucial for further management: metastases require an active approach while observation alone is sufficient in non-functional adenoma.

Follow-up examinations with imaging techniques are a widely discussed issue in incidentalomas. No general consensus on the need for further follow-up CT examinations and their frequency has been reached so $\operatorname{far}^{82,83}$.

In summary, if an incidentaloma has a density of less than $10 \mathrm{HU}$ on CT, it is an adenoma and the diagnosis is definitive (an exception is myelolipoma, with its appearance with negative densities causing no diagnostic confusion). If an incidentaloma has a density of more than $10 \mathrm{HU}$ and washout characteristics are not unequivocal, there are two strategies for follow-up management. Firstly, the examination can be repeated within a certain time period in order to ascertain whether or not the incidentaloma has distinctly enlarged. Secondly, a PET/CT scan can be performed, in which case benign nature can be expected in the absence of radiopharmaceutical accumulation.

\section{CONCLUSION}

The issue of adrenal disease is increasingly current due to major advances in laboratory diagnosis, genetics, options of imaging techniques, and, not least, major progress in surgical techniques for these conditions. Clinically most significant pathological findings in the adrenal gland include adenoma, phaeochromocytoma, carcinoma, and metastases.

These findings may be non-functional, but may also be associated with clinical syndromes. Also very relevant are adrenal incidentalomas due to the increasing frequency of their detection because of the increasing availability and development of imaging techniques.

\section{AUTHORSHIP CONTRIBUTIONS}

Manuscript writing and literature search: F.C. Contribution on radionuclide methods: P.K. Contribution on pathology and histology: T.T.

\section{CONFLICT OF INTEREST STATEMENT}

None declared.

\section{REFERENCES}

1. Pacák K, Lazúrová I. Endokrinní nádory nadledvin v současné klinické praxi. Praha: Galén 2011.

2. Rossi GP, Seccia TM, Pessina AC. Primary aldosteronism - part I: prevalence, screening, and selection of cases for adrenal vein sampling. J Nephrol 2008;21(4):447-54.

3. Kaplan NM. The current epidemic of primary aldosteronism: cause and consequences. J Hypertens 2004;22(5):863-9.

4. Funder JW, Carey RM, Fardella C, Gomez-Sanchez, CE, Mantero F, Stowasser M, Young WF Jr, Montori VM. Case detection, diagnosis, and treatment of patients with primary aldosteronism: an Endocrine Society clinical practice guideline. J Clin Endocrinol Metab 2008;93(9):3266-81.

5. Čtvrtlík F, Köcher M, Černá M, Václavík J, Hartmann I. Současný stav v diagnostice primárního hyperaldosteronismu. Ces Radiol 2012;66(2):139-47.

6. Ballon M, Ceral J, Solař M, Krajina A, Raupach J, Ungermann L. Je průkaz adenomu nadledviny u pacientů s primárním hyperaldosteronizmem dostatečný pro indikaci adrenalektomie? Vnitř Lék 2009;55(6):555-9 (in Czech).

7. lacobone M, Citton M, Viel G, Boetto R, Bonadio I, Tropea S, Mantero F, Rossi GP, Fassina A, Nitti D, Favia G. Unilateral adrenal hyperplasia: A novel cause of surgically correctable primary hyperaldosteronism. Surgery 2012;152(6):1248-55.

8. Kempers MJ, Lenders JW, van Outheusden L, van der Wilt GJ, Schultze Kool LJ, Hermus AR, Deinum J. Systematic review: diagnostic procedures to differentiate unilateral from bilateral adrenal abnormality in primary aldosteronism. Ann Intern Med 2009;151(5):329-37.

9. Nishikawa T, Omura M, Satoh F, Shibata H, Takahashi K, Tamura N, Tanabe A. Guidelines for the diagnosis and treatment of primary aldosteronism. Task Force Committee on Primary Aldosteronism, The Japan Endocrine Society. Endocr J 2011;58(9):711-21.

10. Takeda Y, Karashima S, Yoneda T. Primary aldosteronism, diagnosis and treatment in Japan. Rev Endocr Metab Disord 2011;12(1):21-5.

11. Korobkin M, Giordano TJ, Brodeur FJ, Francis IR, Sigelnam ES, Quint LE, Dunnick NR, Heiken JP, Wangh H. Adrenal adenomas: relationship between histologic lipid and CT and MR findings. Radiology 1996;200:743-7. 
12. Boland GW, Blake MA, Hahn PF, Mayo-Smith WW. Incidental adrenal lesions: principles, techniques, and algorithms for imaging characterization. Radiology 2008;249(3):756-75.

13. Matsuura T, Takase K, Ota H, Yamada T, Sato A, Satoh F, Takahash S. Radiologic Anatomy of the Right Adrenal Vein: Preliminary Experience with MDCT Am. J Roentgenol 2008;191:402-8.

14. Boland, Dwamena BA, Jagtiani Sangwaiya M, Boland GW, Dwamena BA, Jagtiani Sangwaiya M, Goehler AG, Blake MA, Hahn PF, Scott JA Kalra MK. Characterization od adrenal masses by using FDG PET: a systematic review and meta-analysis of diagnostic test performance. Radiology 2011;259(1):117-26.

15. Elder EE, Elder G, Larsson C. Pheochromocytoma and functional paraganglioma syndrome: no longer the 10\% tumor. J Surg Oncol 2005;89(3):193-201.

16. Lenders JW, Eisenhofer G, Mannelli M, Pacak K. Phaeochromocytoma. Lancet 2005;366(9486):665-75.

17. Neumann HP, Bausch B, McWhinney SR, Bender BU, Gimm O, Franke G, Schipper J, Klisch J, Altehoefer C, Zerres K, Januszewicz A, Eng C, Smith WM, Munk R, Manz T, Glaesker S, Apel TW, Treier M, Reineke M,Walz MK, Hoang-Vu C, Brauckhoff M, Klein-Franke A, Klose P Schmidt H, Maier-Woelfle M, Peçzkowska M,Szmigielski C, Eng C Freiburg-Warsaw-Columbus Pheochromocytoma Study Group. Germ-line mutations in nonsyndromic pheochromocytoma. N Eng J Med 2002;346(19):1459-66.

18. Qin Y, Yao L, King EE, Buddavarapu K, Lenci RE, Chocron ES, Lechleiter JD, Sass M, Aronin N, Schiavi F,Boaretto F, Opocher G, Toledo RA Toledo SP, Stiles C, Aguiar RC, Dahia PL. Germline mutations in TMEM127 confer susceptibility to pheochromocytoma. Nat Genet 2010;42(3):229-33.

19. Baysal BE, Ferrell RE, Willett-Brozick JE, Lawrence EC, Myssiorek D, Bosch A, van der Mey A, Taschner PE, Rubinstein WS, Myers EN Richard CW 3rd, Cornelisse CJ, Devilee P, Devlin B. Mutations in SDHD, a mitochondrial complex II gene, in hereditary paraganglioma. Science 2000;287(5454):848-51.

20. Niemann S, Müller U. Mutations in SDHC cause autosomal dominant paraganglioma, type 3. Nat Genet 2000;26(3):268-70.

21. Astuti D, Latif F, Dallol A, Dahia PL, Douglas F, George E, Sköldberg F, Husebye ES, Eng C, Maher ER. Gene mutations in the succinate dehydrogenase subunit SDHB cause susceptibility to familial pheochromocytoma and to familial paraganglioma. Am J Hum Genet 2001;69(1):49-54.

22. Karasek D, Shah U, Frysak Z, Stratakis C, Pacak K. An update on the genetics of pheochromocytoma. J Hum Hypertens 2013;27(3):141-7.

23. Brouwers FM, Eisenhofer G, Tao JJ, Kant JA, Adams KT, Linehan WM Pacak K. High frequency of SDHB germline mutations in patients with malignant catecholamine-producing paragangliomas: implications for genetic testing. J Clin Endocrinol Metab 2006;91(11):45059.

24. de Wailly $P$, Oragano L, Radé F, Beaulieu A, Arnault V, Levillain $P$, Kraimps JL. Malignant pheochromocytoma: new malignancy criteria. Langenbecks Arch Surg 2012;397(2):239-46.

25. Pacak K, Linehan WM, Eisenhofer G, Walther MM, Goldstein DS. Recent advances in genetics, diagnosis, localization, and treatment of pheochromocytoma. Ann Intern Med 2001;134(4):315-29.

26. Chen H, Sippel RS, O'Dorisio MS, Vinik Al, Lloyd RV, Pacak K; North American Neuroendocrine Tumor Society (NANETS). The North American Neuroendocrine Tumor Society consensus guideline for the diagnosis and management of neuroendocrine tumors: pheochromocytoma, paraganglioma, and medullary thyroid cancer. Pancreas 2010;39(6):775-83.

27. Lenders JW, Pacak K, Walther MM, Linehan WM, Mannelli M, Friberg P, Keiser HR, Goldstein DS, Eisenhofer G. Biochemical diagnosis of pheochromocytoma: which test is best? JAMA 2002;287(11):142734.

28. Eisenhofer G, Siegert G, Kotzerke J, Bornstein SR, Pacak K. Current progress and future challenges in the biochemical diagnosis and treatment of pheochromocytomas and paragangliomas. Horm Metab Res 2008;40(5):329-37.

29. Eisenhofer G, Goldstein DS, Walther MM, Friberg P, Lenders JW, Keiser HR, Pacak K. Biochemical diagnosis of pheochromocytoma: how to distinguish true- from false-positive test results. J Clin Endocrinol Metab 2003;88(6):2656-66.

30. Pacak K. Preoperative management of the pheochromocytoma patient. Pacak K. J Clin Endocrinol Metab 2007;92(11):4069-79.
31. Perel $Y$, Sclumberger M, Marguerite G, Alos N, Revillon $Y$, Sommelet D, De Lumley L, Flamant F, Dyon JF, Lutz P, Heloury H, Lemerle J. Pheochromocytoma and paraganglionoma in children: a report of 24 cases of the French Society of Pediatric Oncology. Pediatr Hematol Oncol 1997;14(5):413-22.

32. Bessell-Browne R, O'Malley ME. CT of Pheochromocytoma and Paraganglioma: Risk of Adverse Events with IV Administration of Nonionic Contrast Material. AJR Am J Roentgenol 2007;188:970-4.

33. Jacques $A E$, Sahdev $A$, Sandrasagara $M$, Goldstein R, Berney $D$, Rockall AG, Chew S, Reznek RH. Adrenal phaeochromocytoma: correlation of MRI appearances with histology and function. Eur Radiol 2008;18(12):2885-92.

34. Taïeb D, Timmers HJ, Hindié E, Guillet BA, Neumann HP, Walz MK, Opocher G, de Herder WW, Boedeker CC, de Krijger RR, Chiti A, Al-Nahhas A, Pacak K, Rubello D; European Association of Nuclear Medicine. EANM 2012 guidelines for radionuclide imaging of phaeochromocytoma and paraganglioma. Eur J Nucl Med Mol Imaging. 2012;39(12):1977-95.

35. Rubello D, Vui C, Casara M, Gross D, Fig LM, Shapiro B. Functiona Scintigraphy of the Adrenal Gland. Eur J Endocrinol 2002;147:13-27. (Pacak K, Eisenhofer G, Goldstein DS. Functional imaging of endocrine tumors: role of positron emission tomography. Endocr Rev 2004;25(4):568-80.

36. Pacak K, Eisenhofer G, Goldstein DS. Functional imaging of endocrine tumors: role of positron emission tomography. Endocr Rev 2004;25(4):568-80.

37. Timmers HJ, Chen CC, Carrasquillo JA, Whatley M, Ling A, Havekes B, Eisenhofer G, Martiniova L, Adams KT, Pacak K. Comparison of 18F-fluoro-L-DOPA, 18F-fluoro-deoxyglucose, and 18F-fluorodopamine PET and 123I-MIBG scintigraphy in the localization of pheochromocytoma and paraganglioma. J Clin Endocrinol Metab. 2009;94(12):4757-67.

38. Fassnacht M, Allolio B. Clinical management of adrenocortical carcinoma. Best Pract Res Clin Endocrinol Metab 2009;23(2):273-89.

39. Grumbach MM, Miller BM, Braunstein GD, Campbell KK, Carney JA, Godley PA, Hartus EL, Lee JK, Oertel YC. Management of the clinically inapparent adrenal mass (incidentaloma). Ann Intern Med 2003;138:424-9.

40. Ganeshan D, Bhosale P, Kundra V. Current update on cytogenetics, taxonomy, diagnosis, and management of adrenocortical carcinoma: what radiologists should know. AJR Am J Roentgenol 2012;199(6):1283-93.

41. Bertherat J, Bertagna X. Pathogenesis of adrenocortical cancer. Best Pract Res Clin Endocrinol Metab 2009; 23(2):261-71.

42. Libè R, Fratticci A, Bertherat J. Adrenocortical cancer: pathophysiology and clinical management. Endocr Relat Cancer 2007;14(1):13-28.

43. Zini L, Porpiglia F, Fassnacht M. Contemporary management of adrenocortical carcinoma. Eur Urol 2011;60(5):1055-65.

44. Lacroix A. Approach to the patient with adrenocortical carcinoma. J Clin Endocrinol Metab 2010;95(11):4812-22.

45. Zhang HM, Perrier ND, Grubbs EG, Sircar K, Ye ZX, Lee JE, Ng CS. CT features and quantification of the characteristics of adrenocortical carcinomas on unenhanced and contrast-enhanced studies. Clin Radiol 2012;67(1):38-46.

46. Johnson PT, Horton KM, Fishman EK. Adrenal mass imaging with multidetector Ct: Pathologic conditions, pearls, and pitfalls. Radiographics 2009;29(5):1333-51.

47. Leboulleux S, Dromain C, Bonniaud G, Aupérin A, Caillou B, Lumbroso J, Sigal R, Baudin E, Schlumberger M. Diagnostic and prognostic value of 18-fluorodeoxyglucose positron emission tomography in adrenocortical carcinoma: a prospective comparison with computed tomography. J Clin Endocrinol Metab 2006;91(3):920-5.

48. Elaini AB, Shetty SK, Chapman VM, Sahani DV, Boland GW, Sweeney AT, Maher MM, Slattery JT, Mueller PR, Blake MA. Improved detection and characterization of adrenal disease with PET-CT. RadioGraphics 2007;27:755-67.

49. Okada $M$, Shimono T, Komeya $Y$, et al. Adrenal masses: the value of additional fluorodeoxyglucose-positron emission tomography/ computed tomography (FDG-PET/CT) in differentiating between benign and malignant lesions. Ann Nucl Med 2009; 23:349-54.

50. Lim JW, Kim HJ, Lee DH, Ko YT. Bilateral adrenal masses: Algorithm approach for diagnosis. Eur Radiol 2005;15S1:455(abstr.).

51. Blake MA, Cronin CG, Boland GW. Adrenal imaging. AJR Am J Roentgenol 2010;194(6):1450-60. 
52. Ferozzi F, Tognini G, Giuliotti S, Zuccoli G, Zompatori M. Unusual tumors of the adrenals: CT, MR findings. Eur Radio 2003;13S1:459(abstr.).

53. Johnson PT. Adrenal Imaging with MDCT: Nonneoplastic Disease. AJR Am J Roentgenol 2009;193(4):1128-35.

54. To'o KJ, Duddalwar VA. Imaging of traumatic adrenal injury. Emerg Radiol 2012;19(6):499-503.

55. Jordan E, Poder L, Courtier J, Sai V, Jung A, Coakley FV. Imaging of nontraumatic adrenal hemorrhage. AJR Am J Roentgeno 2012;199(1):W91-8.

56. Berland LL, Silverman SG, Gore RM, Mayo-Smith WW, Megibow AJ, Yee J, Brink JA, Baker ME, Federle MP, Foley WD, Francis IR, Herts BR Israel GM, Krinsky G, Platt JF, Shuman WP, Taylor AJ. Managing incidental findings on abdominal CT: white paper of the ACR incidenta findings committee. J Am Coll Radiol 2010;7(10):754-73.

57. Vlahos I. CT of the adrenal: not just distinguishing non-adenoma versus adenoma. Clin Radiol 2012,67(1):47-8.

58. Young WF. The incidentally discovered adrenal mass. N Engl J Med 2007;356(6):601-10.

59. Ctvrtlík F, Herman M, Student V, Tichá V, Minarík J. Differential diagnosis of incidentally detected adrenal masses revealed on routine abdominal CT. Eur J Radiol 2009;69(2):243-52.

60. Grumbach MM, Miller BM, Braunstein GD, Campbell KK, Carney JA, Godley PA, Hartus EL, Lee JK, Oertel YC. Management of the clinically inapparent adrenal mass (incidentaloma). Ann Intern Med 2003;138(5):424-9.

61. Dunnick NR, Korobkin M. Imaging of adrenal incidentalomas: current status. AJR Am J Roentgenol 2002;179(3):559-68.

62. Hamrahian AH, loachimescu AG, Remer EM, Motta-Ramirez G, Bogabathina H, Levin HS, Reddy S, Gill IS, Siperstein A, Bravo EL. Clinical Utility of Noncontrast Computed tomography Attenuation Value (Hounsfield Units) to Differentiate Adrenal Adenomas/ Hyperplasias from Nonadenomas: Cleveland Clinic Experience. J Clin Endocrinol Metab 2005;90(2):871-7.

63. Mayo-Smith WW, Boland GW, Noto RB, Lee MJ. State-of-the-art adrenal imaging. Radiographics 2001;21(4):995-1012.

64. Udelsman R, Fishman EK, Radiology of the adrenal. Endocrino Metab Clin North Am 2000;29(1):27-42.

65. Kebapci M, Kaya T, Gorbuz E Adapinar B, Kebapci N. Differentiation af adrenal adenomas (lipid rich and lipid poor) from nonadenomas by use of washout characteristics on delayed enhanced CT. Abdom Imag 2003;28(5):709-15.

66. Caoili EM, Korobkin M, Francis IR, Cohan RH, Platt JF, Dunnick NR, Raghupathi Kl. Adrenal masses: characterization with combined unenhanced and delayed enhanced CT. Radiology 2002;222(3):629-33.

67. Szolar DH, Korobkin M, Reittner P, Berghold A, Bauernhofer T, Trummer $\mathrm{H}$, Schoellnast $\mathrm{H}$, Preidler KW, Samonigg H. Adrenocortical carcinomas and adrenal pheochromocytomas: mass and enhancement loss evaluation at delayed contrast-enhanced CT. Radiology 2005;234(2):479-85.

68. Kamiyama T, Fukukura Y, Yoneyama T, Takumi K, Nakajo M. Distinguishing adrenal adenomas from nonadenomas: combined use of diagnostic parameters of unenhanced and short 5-minute dynamic enhanced CT protocol. Radiology 2009;250(2):474-81.
69. Lee MJ, Hahn PF, Papanicolaou N, Egglin TK, Saini S, Mueller PR, Simeone JF. Benign and malignant adrenal masses: CT distinction with attenuation coefficients, size, and observer analysis. Radiology $1991 ; 179(2): 415-8$

70. Boland GW, Lee MJ, Gazelle GS, Halpern EF, McNicholas MM, Mueller PR. Characterization of adrenal masses using unenhanced CT: an analysis of the CT literature. AJR Am J Roentgenol 1998;171(1):201-4.

71. Ganeshan D, Bhosale P, Kundra V. Current update on cytogenetics, taxonomy, diagnosis, and management of adrenocortical carcinoma: what radiologists should know. AJR Am J Roentgenol 2012;199(6):1283-93.

72. Caoili EM, Korobkin M, Francis IR, Cohan RH, Platt JF, Dunnick NR, Raghupathi KI. Adrenal masses: characterization with combined unenhanced and delayed enhanced CT. Radiology 2002;222(3):629-33.

73. Peña CS, Boland GW, Hahn PF, Lee MJ, Mueller PR. Characterization of indeterminate (lipid-poor) adrenal masses: use of washout characteristics at contrast-enhanced CT. Radiology 2000;217(3):798-802.

74. Caoili EM, Korobkin M, Francis IR, Cohan RH, Dunnick NR. Delayed enhanced CT of lipid-poor adrenal adenomas.AJR Am J Roentgenol 2000;175(5):1411-5

75. Blake MA, Kalra MK, Sweeney AT, Lucey BC, Maher MM, Sahani DV, Halpern EF, Mueller PR, Hahn PF, Boland GW. Distinguishing benign from malignant adrenal masses: multi-detector row $C T$ protocol with 10-minute delay. Radiology 2006; 238(2):578-85.

76. Korobkin M, Brodeur FJ, Francis I, Quint LE, Dunnick NR, Londy F. CT time- attenuation washout curves of adrenal adenomas and nonadenomas. AJR Am J Roentgenol 1998;170(3):747-52.

77. Park SW, Kim TN, Yoon JH, Kim TH, Chung JM, Jeon UB, Lee W. The washout rate on the delayed $C T$ image as a diagnostic tool for adrenal adenoma verified by pathology: a multicenter study. Int Urol Nephrol 2012;44(5):1397-402.

78. Mantero F, Terzolo M, Arnaldi G, Osella G, Masini AM, Ali A, Giovagnetti M., Opocher G, Angeli AA. Survey on Adrenal Incidentaloma in Italy. J Clin Endocrinol Metab 2000;85(2):637-44.

79. Rossi R, Tauchmanova L, Luciano A, Martino M, Battista C, Viscovo L, Nuzzo V, Lombardi G. Subclinical Cushing's Syndrome in Patients with Adrenal Incidentaloma: Clinical and Biochemical Features. J Clin Endocrinol Metab 2000;85(4):1440-8.

80. Boland GW, Blake MA, Hahn PF, Mayo-Smith WW. Incidental adrenal lesions: principles, techniques, and algorithms for imaging characterization. Radiology 2008;249(3):756-75.

81. Arnaldi G, Boscaro M. Adrenal incidentaloma. Best Pract Res Clin Endocrinol Metab. 2012;26(4):405-19.

82. Zeiger MA, Thompson GB, Duh QY, Hamrahian AH, Angelos $P$, Elaraj D, Fishman E, Kharlip J. American Association of Clinical Endocrinologists; American Association of Endocrine Surgeons. American Association of Clinical Endocrinologists and American Association of Endocrine Surgeons Medical Guidelines for the Management of Adrenal Incidentalomas: executive summary of recommendations. Endocr Pract 2009;15(5):450-3.

83. Aron D, Terzolo M, Cawood TJ. Adrenal incidentalomas. Best Pract Res Clin Endocrinol Metab 2012:26(1):69-82. 